\title{
Chapter 8 \\ Surface Improvement for Biocompatibility of Ti-6Al-4V by Dealloying in Metallic Melt
}

\author{
Yuichi Fukuzumi, Takeshi Wada, and Hidemi Kato
}

\begin{abstract}
Dealloying is known to be a powerful method to produce porous materials mainly with noble metals because the mechanism involves the selective dissolution of specific element(s) by corrosion in acid/alkali aqueous solutions. Recently, an alternative dealloying method has been developed by our research group using a metallic melt in place of the corrosive aqueous solution. In this study, using the novel dealloying method using a metallic melt, toxic Al element, was successfully removed from the surface of Ti-6Al-4V, which has been used for biomedical applications, for improving their biocompatibility. The toxic ion release from the overall sample did not effectively decrease because of the substantial surface area that developed using the dealloying method. By optimizing the dealloying conditions to suppress surface area development, drastic improvement in the biocompatibility of this Ti alloy is expected.
\end{abstract}

Keywords Biocompatibility • Dealloying • Surface improvement • Ti-6Al-4V

\subsection{Introduction}

Biomaterials are becoming more important for our better quality of life. When a person temporally or permanently loses particular biofunction by illness or injury, biomaterials are required to compensate it. The properties required for biomaterials are mainly divided into mechanical conditions such as strength, toughness, elasticity and the biological conditions such as toxicity, biodegradation and carcinogenicity. The Ti-based alloys are promising biomedical material because they can combine excellent mechanical and biological properties [1]. Among the various Ti-based alloys, the Ti-6Al-4V alloy one of the most frequently used metallic biomaterials. This alloy is two-phase alloy in which $\mathrm{Al}$ element acts as an

\author{
Y. Fukuzumi \\ Graduate Student, Graduate School of Engineering, Tohoku University, \\ Sendai 980-8579, Japan \\ T. Wada $\bullet$ H. Kato $(\bowtie)$ \\ Institute for Materials Research, Tohoku University, 2-1-1 Katahira, \\ Aoba-ku, Sendai 980-8577, Japan \\ e-mail: hikato@imr.tohoku.ac.jp \\ (C) The Author(s) 2015 \\ K. Sasaki et al. (eds.), Interface Oral Health Science 2014, \\ DOI 10.1007/978-4-431-55192-8_8
}


$\alpha$-phase (hexagonal close packed phase) stabilizer and V acts as a $\beta$-phase (bodycentered cubic phase) stabilizer. This two-phase alloy was originally developed as a material for aircraft, therefore, this alloy combines high strength, high toughness and low density. As for the biomedical use, the Ti-6Al-4V alloy is often used as a load-bearing components such as artificial bone and dental implant [2]. Despite excellent mechanical and biological properties from this alloy, the cytotoxicity problem due to the release of $\mathrm{V}$ and $\mathrm{Al}$ ion in vivo remains unsolved [3]. To make this alloy more biocompatible, extensive researches for developing two-phase alloy without using $\mathrm{V}$ and $\mathrm{Al}[4]$ and also the establishing surface improvement technology are ongoing [5]. Unlike these conventional works, our approach is to utilize a dealloying method to dissolve toxic elements from an alloy by immersion into a metallic melt [6-10]. In this study, we apply this dealloying method to remove toxic elements from the surface of biomedical alloys and then investigate the resulting effect on the biocompatibility.

\subsection{Dealloying in a Metallic Melt}

When we mix two elements, the free energy change due to this event is

$$
\Delta G_{\text {mix }}=\Delta H_{\text {mix }}-T \Delta S_{\text {mix }}
$$

where $\Delta H_{\text {mix }}$ is the heat of mixing, $\Delta S_{\text {mix }}$ is the entropy of mixing, and $T$ is the absolute temperature. Usually, the entropy increases after mixing. Therefore, if $\Delta H_{\text {mix }}<0$, the $\Delta G_{\text {mix }}<0$, and the mixing reaction can occur spontaneously from a thermodynamic point of view. On the other hand, if $\Delta H_{\text {mix }}>0$ the sign (positive or negative) of $\Delta G_{\text {mix }}$ depends on the temperature. If the temperature is adequately controlled to make the enthalpy term larger than the entropy term, then $\Delta G_{\text {mix }}>0$, and we can avoid the mixture of the two elements. Here we dip an A-B binary alloy precursor into a metallic melt consisting of element $C$. If the heat of mixing between elements $\mathrm{B}$ and $\mathrm{C}$ is negative, i.e., $\Delta H_{\mathrm{mix}, \mathrm{B}-\mathrm{C}}<0$ and if the heat of mixing between elements $\mathrm{A}$ and $\mathrm{C}$ is positive, i.e., $\Delta H_{\mathrm{mix}, \mathrm{A}-\mathrm{C}}>0$, then by controlling temperature adequately only element $\mathrm{B}$ dissolves from the precursor into the $\mathrm{C}$ melt; since element $\mathrm{A}$ is rejected from the $\mathrm{C}$ melt, it is expected to self-organize into a porous structure by surface diffusion in the same manner as that of the ordinary dealloying method in an aqueous solution [11]. Figure 8.1 shows a schematic of this novel dealloying method that involves the selective dissolution of B atoms (orange) in the $\mathrm{C}$ atom melt (pink) and surface diffusion of the remaining $\mathrm{A}$ atoms (yellowish green). Figure 8.2 summarizes this "triangle" relationship in terms of the heat of mixing among elements $\mathrm{A}, \mathrm{B}$, and $\mathrm{C}$ required for the dealloying reaction in a metallic melt. We have to calculate the accurate value for the heat of mixing by considering the temperature and chemical composition for designing the dealloying reaction. However, this is sometimes complicated. The heat of mixing between the transition metals, and the transition metals and metalloids can be obtained from the 


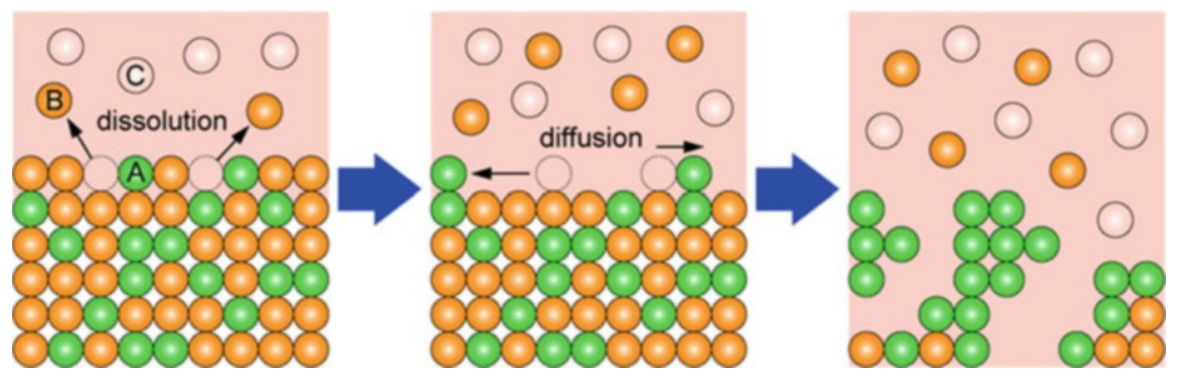

Fig. 8.1 Schematic of the dealloying method using a metallic melt, where atom B (orange) dissolves into a melt composed of $\mathrm{C}$ atoms (pink), and the remaining atom A (yellowish green) self-organizes into a porous structure by surface diffusion

Fig. 8.2 Triangle relationship of the enthalpies of mixing among elements $\mathrm{A}, \mathrm{B}$, and $\mathrm{C}$ for dealloying in a metallic melt

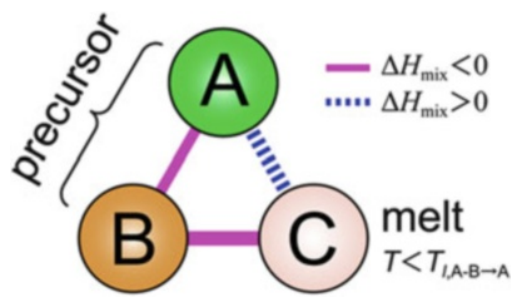

(1) Reaction designing

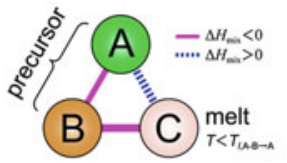

(2) Precursor preparation

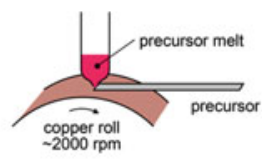

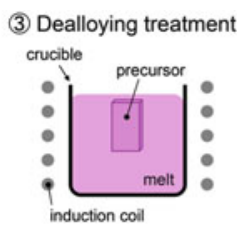

(4) Etching melt element
beaker acid/alkali solution

Fig. 8.3 Schematic of the process of porous metal preparation using dealloying in a metallic melt

table in Boer and Perrifor [12], the values of which are approximately calculated by the Miedema model, and that of other metals can be obtained from the table constructed by Takeuchi et al. [13]. In our study, we first identify the candidates for elements A, B, and C from the tables in Boer and Perrifor [12] and Takeuchi and Inoue [13] and we then confirm the relationships A-B and B-C (mixture) and A-C (separation) by the related binary phase diagrams. Here, we summarize the preparation procedures for nanoporous metals by dealloying in a metallic melt, as they are schematically shown in Fig. 8.3.

1. Selection of A-B-C elements, which satisfy the triangle relationship of the heats of mixing. (tables of values of heat of mixing and equilibrium phase diagrams can be used).

2. Preparation of the A-B alloy precursor. 
3. Selective dissolution of element $B$ from the A-B precursor into the $\mathrm{C}$ metal melt (formation of the porous structure).

4. Removal of the $\mathrm{C}$ element by etching with an acid or alkaline solution (the remaining A component must be inert in the solution).

\subsection{Surface Improvement of Ti-6Al-4V Alloy by Dealloying with a Metallic Melt [14]}

\subsubsection{Morphology and Composition Change by Dealloying}

The Ti-6Al-4V alloy, which consists of both $\alpha$-Ti and $\beta$-Ti phases, is one of the promising biomedical materials among Ti alloys. However, the $\mathrm{Al}$ and $\mathrm{V}$ in this alloy are known to be cytotoxic elements. We attempted selective removal of the toxic element(s) from the surface of the Ti-6Al-4V alloy using dealloying with a metallic melt. In this section, we demonstrate the selected removal of $\mathrm{Al}$ as the first step for improving the biocompatibility of this alloy. Based on the triangle relationship of values of heat of mixing, the $\mathrm{Mg}$ melt can be used due to the negative enthalpy of mixing with $\mathrm{Al}$ and the positive enthalpy of mixing with both $\mathrm{Ti}$ and V. This relationship is illustrated in Fig. 8.4. Figure 8.5 and Table 8.1 exhibit SEM images and the corresponding results of EDX analysis of the Ti-6Al-4V surface dealloyed in a $\mathrm{Mg}$ melt at $1,148 \mathrm{~K}$ for $0.3-7.2 \mathrm{ks}$, respectively. An increasing immersion time resulted in the coarsening of the porous structure on the surface. Similarly, an increase in the immersion temperature from 1,048 to $1,148 \mathrm{~K}$ under the fixed immersion time of $1.2 \mathrm{ks}$ resulted in the coarsening of the porous structure on the surface. It has been generally observed that the morphology and chemical composition of the dealloyed sample depend on the immersion time and temperature of the melt during dealloying treatment [10]. An increased immersion time up to $1.2 \mathrm{ks}$ at $1,148 \mathrm{~K}$ resulted in a slight decrease in $\mathrm{Al}$ concentration. However, a further increase in the immersion time resulted in an increase of $\mathrm{Al}$ content. This is probably due to the dissolution of $\mathrm{Ti}$ into the $\mathrm{Mg}$ melt, which is suggested by the observed concentration decrease in $\mathrm{Ti}$ with immersion time that became dominant after $1.2 \mathrm{ks}$. To confirm dissolution of Ti, a cp-Ti rod was immersed into a Mg melt at $1,184 \mathrm{~K}$ for $1.8 \mathrm{ks}$ in a carbon crucible. The mass loss, which is defined by (mass loss $)=($ mass of initial cp-Ti $)-($ mass of treated cp-Ti), was estimated to be $\sim 6 \mathrm{mg}$ (Fig. 8.6). Therefore, dissolution of Ti was confirmed to occur in the Mg melt,

Fig. 8.4 Triangle relationship of the enthalpies of mixing among $\mathrm{Ti}, \mathrm{V}, \mathrm{Al}$, and $\mathrm{Mg}$

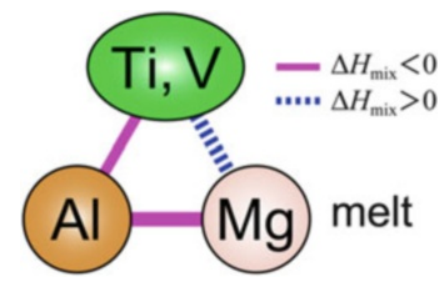



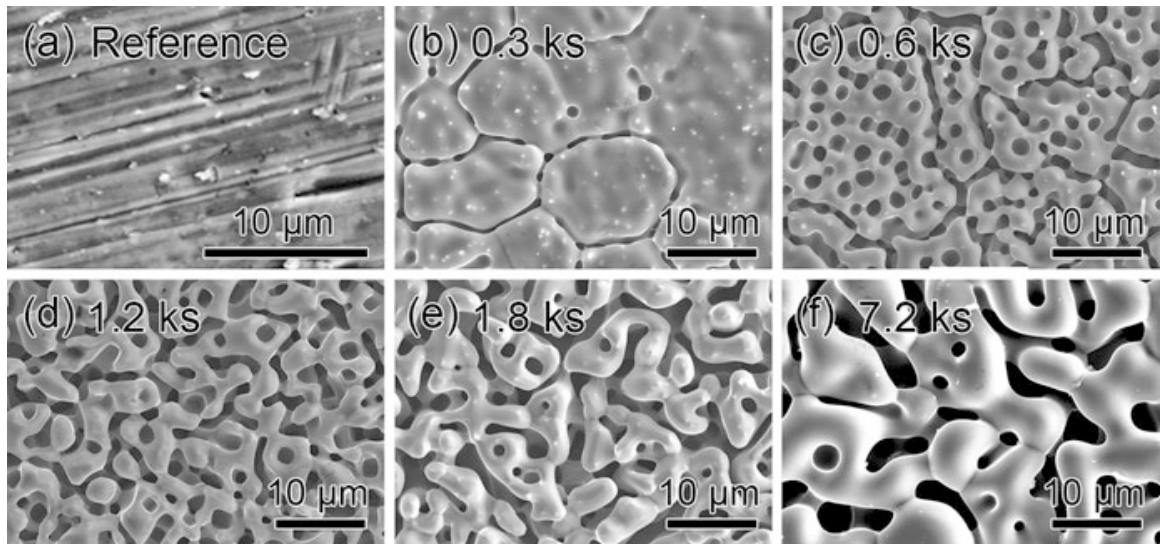

Fig. 8.5 SEM images of the surface of Ti-6Al-4V disks immersed in a Mg melt at $1,148 \mathrm{~K}$ for $0 \mathrm{~s}$ (reference) (a), $0.3 \mathrm{ks}(\mathbf{b}), 0.6 \mathrm{ks}(\mathbf{c}), 1.2 \mathrm{ks}(\mathbf{d}), 1.8 \mathrm{ks}(\mathbf{e})$, and $7.2 \mathrm{ks}$ (f) followed by leaching of $\mathrm{Mg}$ phases in a nitric acid aqueous solution. Scratches shown in (a) are from the mechanical polishing process

Table 8.1 EDX analysis results for $\mathrm{Ti}, \mathrm{Al}$, and $\mathrm{V}$ concentrations (wt.\%) of the dealloyed samples shown in Fig. 8.5

\begin{tabular}{l|l|l|l}
\hline & $\mathrm{Ti}$ & $\mathrm{Al}$ & $\mathrm{V}$ \\
\hline Reference & 90.9 & 6.5 & 4.4 \\
\hline $0.3 \mathrm{ks}$ & 88.8 & 6.8 & 4.4 \\
\hline $0.6 \mathrm{ks}$ & 85.4 & 5.1 & 9.8 \\
\hline $1.2 \mathrm{ks}$ & 88.9 & 5.0 & 6.2 \\
\hline $1.8 \mathrm{ks}$ & 90.1 & 5.7 & 4.21 \\
\hline $7.2 \mathrm{ks}$ & 83.9 & 11.1 & 5.1 \\
\hline
\end{tabular}

Fig. 8.6 Dependence of crucible material (carbon and titanium) on mass loss of a cp-Ti rod immersed in a Mg melt at $1,148 \mathrm{~K}$ for $1.8 \mathrm{ks}$

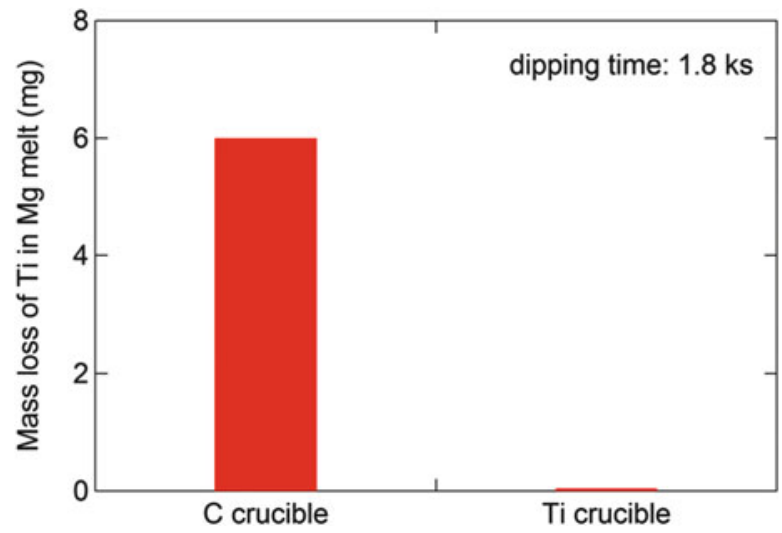

although the heat of mixing between them is positive. Interestingly, it is found that the mass loss of cp-Ti is well suppressed when a Ti crucible is used, as shown in Fig. 8.6. These results suggest that the crucible material affects the morphology and composition. Here, we investigated effect of crucible materials composed of Mo, C, 


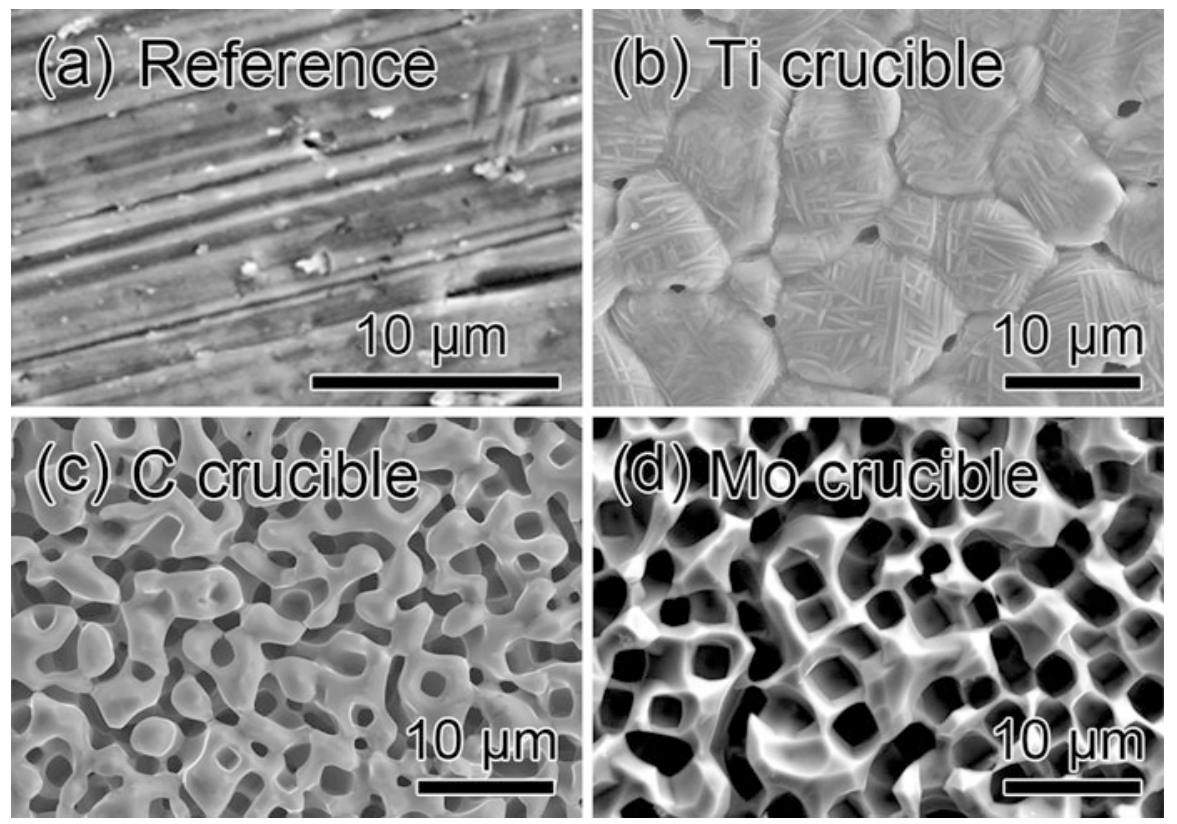

Fig. 8.7 SEM images of the surface of Ti-6Al-4V dealloyed in a Mg melt at 1,148 $\mathrm{K}$ for $1.2 \mathrm{ks}$ using various crucibles: Ti (b), C (c), and Mo (d). Nondealloyed Ti-6Al-4V is shown in (a) for a reference

Table 8.2 EDX analysis results for $\mathrm{Ti}, \mathrm{Al}$, and $\mathrm{V}$ concentrations (wt.\%) on the surface of the samples shown in Fig. 8.7

\begin{tabular}{l|l|l|l}
\hline & $\mathrm{Ti}$ & $\mathrm{Al}$ & $\mathrm{V}$ \\
\hline Reference & 90.9 & 6.5 & 2.6 \\
\hline Ti crucible & 93.1 & 3.4 & 3.6 \\
\hline C crucible & 88.9 & 5.0 & 6.2 \\
\hline Mo crucible & 93.1 & 4.2 & 5.2 \\
\hline
\end{tabular}

and $\mathrm{Ti}$, which are all immiscible with $\mathrm{Mg}$ according to the related phase diagrams. Figure 8.7 and Table 8.2 exhibit SEM images and the corresponding results of EDX analysis of the surface of Ti-6Al-4V dealloyed at $1,148 \mathrm{~K}$ for $1.2 \mathrm{ks}$ using different crucibles, together with an untreated sample for comparison. On the surface of the untreated sample, only the linear scratches formed during the machining process are observed. However, the dealloyed samples using $\mathrm{C}$ and Mo crucibles show a welldeveloped porous structure on their surfaces. On the contrary, the sample dealloyed in a Ti crucible shows a small number of isolated pores at the grain boundary on the surface. Regardless of crucible materials, the Al concentration decreased after the dealloying treatment. This result indicates that when Ti-6Al-4V is immersed into $\mathrm{Mg}$, a mass change occurs due to the dissolution of $\mathrm{Ti}$, as schematically shown in Fig. 8.8. If the $\mathrm{Ti}$ crucible is used, dissolution of $\mathrm{Ti}$ from the crucible possibly occurs. The fact that the $\mathrm{Al}$ and $\mathrm{V}$ concentration on the surface decreased 
Fig. 8.8 Schematic of differences in the dealloying using $\mathrm{C}$ and Mo crucibles (left) and a Ti crucible (right)
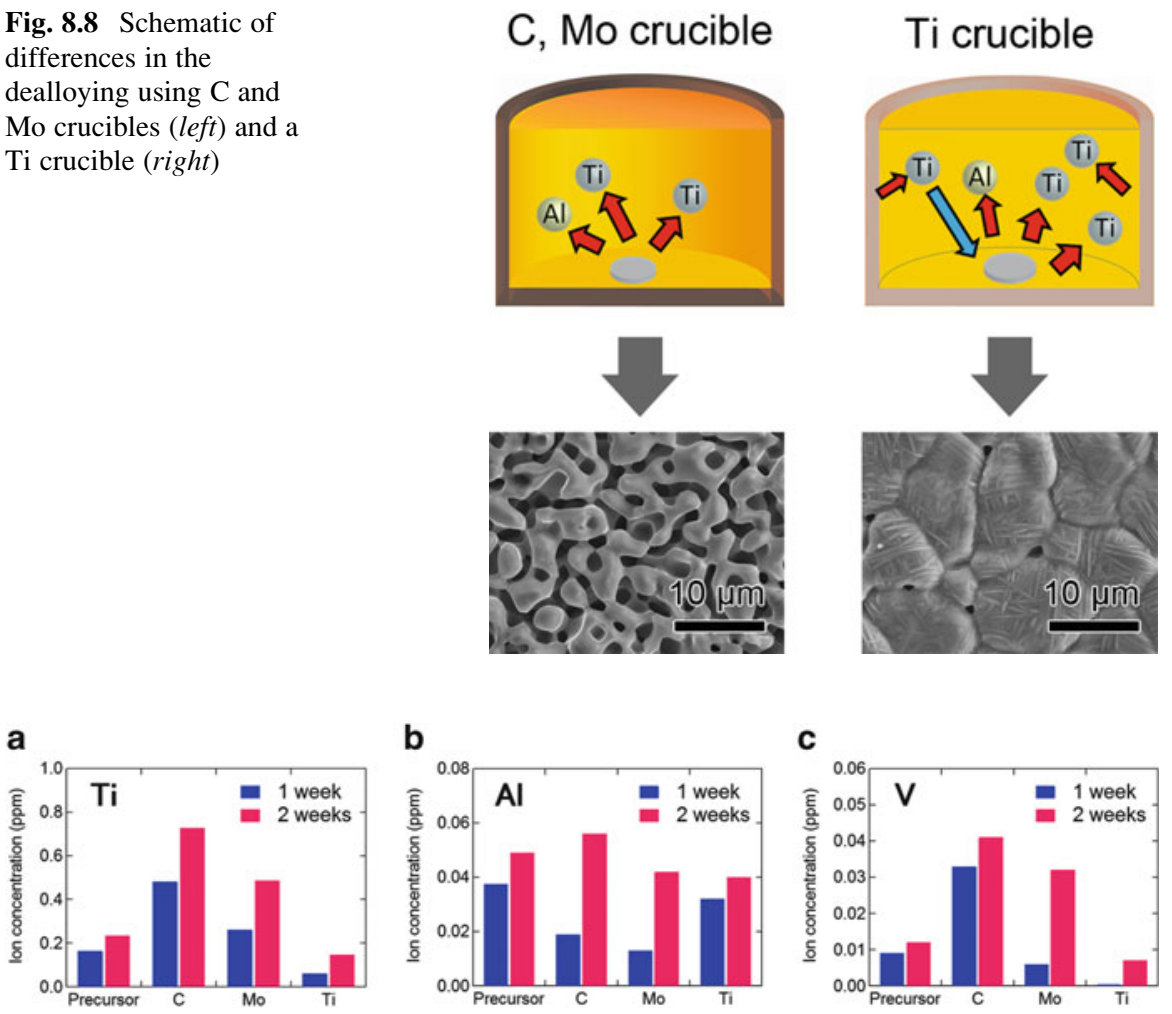

Fig. 8.9 Influence of crucible material for dealloying treatment on the amount of $\mathrm{Ti}(\mathbf{a}), \mathrm{Al}$ (b), and $\mathrm{V}$ (c) ion release from the dealloyed Ti-6Al-4V disk in a simulated body fluid (SBF) after 1 and 2 weeks

without developing a nanoporous structure suggests that $\mathrm{Ti}$ atoms dissolved from Ti crucible into the Mg melt deposited onto the Ti-6Al-4V surface simultaneously with dealloying.

\subsubsection{Effect of Crucible Material on Ion Release of Dealloyed Ti-6Al-4V}

As described in the above section, the surface feature of the dealloyed Ti-6Al-4V sample strongly depends on the crucible material. Such effect is expected to significantly affect the ion release behavior of the dealloyed samples. Therefore, the effects of crucible material on ion release of dealloyed Ti-6Al-4V were studied. Figure 8.9 shows the results of ion release from Ti-6Al-4V dealloyed using crucibles made of $\mathrm{C}$, Mo, and Ti after 1 and 2 weeks in simulated body fluid $(\mathrm{SBF})$. The amount of $\mathrm{Al}$ ion release decreased for all cases because of the 
dealloying effect. The amount of $\mathrm{Ti}$ and $\mathrm{V}$ ion release increased for the sample dealloyed using $\mathrm{C}$ and Mo crucibles due to the increase of surface area owing to the well-developed porous structure. In contrast, the amount of $\mathrm{Ti}$ and $\mathrm{V}$ ions released from Ti-6Al-4V dealloyed using a Ti crucible decreased due to the formation of a less porous surface composed of a Ti-rich phase. That the surface structure and composition might depend on the crucible material was beyond our expectations; however, this effect is potentially useful for controlling the ion release behavior as well as the surface structure of the dealloyed sample.

\subsection{Summary}

Using the dealloying method in a metallic melt, selective removal of toxic $\mathrm{Al}$ element from the surface of and Ti-6Al-4V alloys, which have been used as biomedical metals, was attempted in order to improve their biocompatibility.

1. By immersing a Ti-6Al-4V alloy into a Mg melt, the surface Al concentration of the Ti-6Al-4V alloy was successfully reduced.

2. The surface morphology and composition of the dealloyed Ti-6Al-4V was found to depend strongly on the crucible materials used during the dealloying treatment. When $\mathrm{C}$ and Mo crucibles were used, not only $\mathrm{Al}$ but $\mathrm{Ti}$ and $\mathrm{V}$ also dissolved into the $\mathrm{Mg}$ melt, resulting in a well-developed porous surface layer. On the other hand, when using a Ti crucible, the $\mathrm{Al}$ and $\mathrm{V}$ surface concentration was successfully reduced by means of a less porous Ti rich surface layer that was considered to have developed due to surface deposition of Ti dissolved from the $\mathrm{Ti}$ crucible into the $\mathrm{Mg}$ melt.

Considering the crucible material, more research is required to optimize the dealloying conditions that can realize a reduction of the surface concentration of a toxic element without increasing the surface area.

Open Access This chapter is distributed under the terms of the Creative Commons Attribution Noncommercial License, which permits any noncommercial use, distribution, and reproduction in any medium, provided the original author(s) and source are credited.

\section{References}

1. Niinomi M, Nakai M, Hieda J. Development of new metallic alloys for biomedical applications. Acta Biomater. 2012;8:3888-903.

2. Geetha M, Singh AK, Asokamani R, Gogia AK. Ti based biomaterials, the ultimate choice for orthopaedic implants - a review. Progr Mater Sci. 2009;54:397-425.

3. Steinemann SG. Corrosion of surgical implants-in vivo and in vitro tests. In: Winter GD, Leray JL, de Groot K, editors. Evaluation of biomaterials, advances in biomaterials. New York: Wiley; 1980. p. 1-34. 
4. Okazaki Y, Rao S, Ito Y, Tateishi T. Corrosion resistance, mechanical properties: corrosion fatigue strength and cytocompatibility of new $\mathrm{Ti}$ alloys without $\mathrm{Al}$ and $\mathrm{V}$. Biomaterials. 1998; 19:1197-215.

5. Liu X, Chu PK, Ding C. Surface modification of titanium, titanium alloys, and related materials for biomedical applications. Mater Sci Eng R. 2004;47:49-121.

6. Wada T, Yubuta K, Inoue A, Kato H. Dealloying by metallic melt. Mater Lett. 2011;65:1076-8.

7. Wada T, Setyawan AD, Yubuta K, Kato H. Nano- to submicro-porous beta-Ti alloy prepared from dealloying in a metallic melt. Scripta Mater. 2011;65:532-5.

8. Wada T, Kato H. Three-dimensional open-cell macroporous iron, chromium and ferritic stainless steel. Scripta Mater. 2013;68:723-6.

9. Kim JW, Wada T, Kim SG, Kato H. Sub-micron porous niobium solid electrolytic capacitor prepared by dealloying in a metallic melt. Mater Lett. 2014;116:223-6.

10. Tsuda M, Wada T, Kato H. Kinetics of formation and coarsening of nanoporous $\alpha$-titanium dealloyed with Mg melt. J Appl Phys. 2013;114(1-8):113503.

11. Forty AJ. Corrosion micromorphology of noble metal alloys and depletion gilding. Nature. 1979;282:597-8.

12. Boer FR, Perrifor DG. Cohesion in metals. Netherlands: Elsevier Science Publishers B.V; 1988.

13. Takeuchi A, Inoue A. Classification of bulk metallic glasses by atomic size difference, heat of mixing and period of constituent elements and its application to characterization of the main alloying element. Mater Trans. 2005;46:2817-29.

14. Fukuzumi Y. Surface modification of Ti-6Al-4V biomaterial by dealloying with metallic melt, Master Thesis. Tohoku University Japan; 2012. 